GEOCHRONOMETRIA 48 (2021): 263-271

DOI 10.1515/geochr-2015-0117

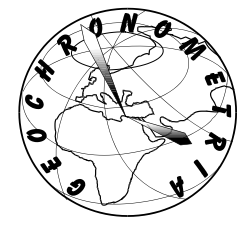

Conference Proceedings of the $5^{\text {th }}$ Asia Pacific Luminescence and Electron Spin Resonance Dating Conference October $15^{\text {th }}-17^{\text {th }}, 2018$, Beijing, China

Guest Editor: Barbara Mauz

\title{
ULTRAFAST COMPONENT EFFECTS ON QUARTZ SINGLE GRAINS DOSE ESTIMATION FROM KHUTAGT UUL MOUNTAINS, MONGOLIA
}

\author{
SARAN TENGIS ${ }^{1}$, SARAN SOLONGO ${ }^{1}$ and RINCHINKHOROL MUNKHTULGA ${ }^{2}$ \\ ${ }^{I}$ Institute of Physics and Technology, Mongolian Academy of Sciences, Ulaanbaatar, Mongolia \\ ${ }_{2}^{2}$ Institute of History and Archaeology, Mongolian Academy of Sciences, Ulaanbaatar, Mongolia
}

Received 15 February 2019

Accepted 12 July 2019

\begin{abstract}
This study presents single-grain optically stimulated luminescence (OSL) results from pottery and sediments from the archaeological site "The burials in Khutag Uul Mountains (Mongolia)". A global fitting procedure was used on a selection of single grains from pottery, $D_{0}$ values obtained were between 16 to $40 \mathrm{~Gy}$ and 25 to $82 \mathrm{~Gy}$ and the equivalent doses $D_{e}$ ranged from $\sim 8$ to $12 \mathrm{~Gy}$ and from $4.2 \pm 0.4$ Gy to $37.3 \pm 2.5$ Gy for pottery and sedimentary quartz, correspondingly.

For pottery, the relative spread in CAM $D_{e}$ values increases as higher precision constraints are applied and lead to significant increases in the relative standard error from $2.7 \%$ to $\sim 7.5 \%$. The number of accepted grains which passed acceptance criteria reduced from 180 to 65 . For sedimentary quartz, there is a trend observed that both MAM $D_{e}$ and FMM $D_{e}$ values increase as higher precision in $D_{e}$ is applied, and the number of accepted grains reduces from 146 to 53 .

The detailed study of the OSL decay curves identified an ultrafast OSL component with the decay rates of $53 \pm 1 \mathrm{~s}^{-1}$ in addition to the fast and medium components and its effect on $D_{e}$ was examined.
\end{abstract}

Keywords: OSL, single grain luminescence, ultrafast component.

\section{INTRODUCTION}

Optically stimulated luminescence (OSL) dating of sediments and thermoluminescence (TL) dating of heated ceramics, terracotta figurines and potteries has proven to be useful in investigating geo-archaeological sites. Especially single-grain quartz optically stimulated luminescence dating has shown to provide reliable ages for samples from a range of archaeological contexts (Guérin et al., 2012; Jacobs et al., 2012; Solongo et al., 2016; So-

Corresponding author: S. Tengis

e-mail: sarans@mas.ac.mn longo et al., 2014). Single grain luminescence dating is often preferred in order to distinguish grains which were well bleached at time of deposition from those incomplete bleached (Jacobs and Roberts, 2007), grains from all mixed-age deposits (Duller, 2008), and to identify post-depositional mixing of sedimentary units (Arnold and Roberts, 2009). The OSL characteristics of the individual grains have been analysed in view of the various factors, among which the statistical uncertainty due to photon counting and instrumental uncertainties to determine $D_{e}$ (Duller, 2008; Thomsen, 2004); the grain-tograin variability in OSL response to the measurement conditions in the luminescence signal intensity (Adamiec, 2005; Jacobs et al., 2006; Thomsen et al., 2002), but also 
the presence of fast, medium and slow components which can be identified using the OSL decay fitting procedures (Bailey et al., 2011) and LM-OSL measurements (Bulur et al., 2002). Separation of a 'clean' fast OSL component is thought to be required for reliable dating, as it is rapidly zeroed by sunlight and has sufficient thermal stability for dating the last few million years (Adamiec et al., 2010; Wintle and Murray, 2006). For multi-grain OSL, the low ratio of fast to medium components (Solongo et al., 2006) could cause the underestimation of equivalent dose $\left(D_{e}\right)$ values. This under-estimation could be corrected, by eliminating grains with a low "fast ratio" (Durcan and Duller, 2011), which is the ratio between the initial signal (dominated by the fast component) and a later signal (dominated by the medium component). Especially for single-grain dating, the dominance of the fast component is assumed but rarely quantified. Recent studies (Duller, 2012; Feathers and Pagonis, 2015) focused on the need to investigate the luminescence characteristics of single grains further and improve the accuracy and precision of equivalent doses.

Our study examines single-grain chronologies for the archaeological site "the burials in Khutag Uul Mountains (Mongolia)", associated with human activities from the Xiongnu period $\left(3^{\text {rd }}\right.$ century $\mathrm{BC}-2^{\text {nd }}$ century $\left.\mathrm{AD}\right)$ and from Turk period (552-745 AD) - using pottery and sedimentary samples from the same archaeological context. Based on the previous findings, e.g. the advantage of luminescence dating at the archaeological site using different dating materials (Solongo et al., 2019), the main aim of the present work includes the study of the luminescence characteristics of single grains from pottery quartz and sedimentary quartz. For single-grain dating, the dominance of the fast component using the fitting procedure will be quantified, and the effect of the ultrafast component on the dose evaluation will be examined and analysed further by identifying the appropriate integration time integral using $\mathrm{D}_{\mathrm{e}}-(\mathrm{t})$ plots.

\section{MATERIALS AND METHODS}

\section{Site and samples}

The Orkhon Valley was the centre of numerous nomadic states; the Xiongnu $\left(3^{\text {rd }}\right.$ century $\mathrm{BC}-1^{\text {st }}$ century AD), Turkic (552-745 AD), and Mongol Empires (12 ${ }^{\text {th }}-$ $14^{\text {th }}$ centuries) succeeded one another in the steppes of Mongolia. Archaeological research in Orkhon Valley has concentrated on numerous steles with runic inscriptions, but also on numerous archaeological burials. Khutag Uul Mountains ( $\left.47^{\circ} 36^{\prime} \mathrm{N}, 102^{\circ} 47^{\prime}\right)$ is located on the left bank of the Khogshin Orkhon River on the eastern edge of the upper Orkhon valley; it was once a tribute to the people of ancient times. The Khutag Uul Cemetery is the largest in its territory. In 2009, during the fieldwork, a total of 121 burial sites were recorded in the south and additionally 43 burials on the east (Bayar et al., 2010), which im- mediately became the $2^{\text {nd }}$ Khutag Uul Mountain Cemetery.

The settlement history at this site and the characteristic types of archaeological monuments, especially the sections of burial structures and tombs have been associated with human activities from the Turkic period. However, the graves under study had similar exterior surface structures mounded by an oval or circular stone construction with a diameter of 6-8 $\mathrm{m}$, reflecting a standard tomb of the Xiongnu period. Pottery fragments L-EVA-1201 and associated sedimentary samples L-EVA-1202 and L-EVA-1203, L-EVA1204 from nearby sites 'MKC 65' (layer 2) and 'MKC 4' (layer 1) were collected taken for single grain measurements (Table S1). The single-grain OSL ages obtained on pottery are compared with singlegrain results from sedimentary quartz that revealed postdepositional mixing due to human activities, during the re-using or re-opening of the burial at a later period, which is known to have occurred during the $5^{\text {th }}-6^{\text {th }}$ century AD (Unpublished Master Thesis Tengis S. 2017)

\section{Sample preparation and measuring facilities}

Sample preparation and luminescence measurements were carried out in the Luminescence laboratory at the MPI for evolutionary anthropology, Leipzig (Germany) and followed the standard procedure reported in (Solongo et al., 2019).

Single grains of quartz were measured using a Risø TL-DA-20 reader (Bøtter-Jensen et al., 2003) fitted with a single grain attachment. A $10 \mathrm{~mW} \mathrm{Nd:} \mathrm{YVO}_{4}$ solid-state diode-pumped green laser was used for quartz singlegrain stimulation, and the signal was detected through Hoya U-340 filters. A $130 \mathrm{~mW}$ infrared (IR) diode emitting at $870 \pm 40 \mathrm{~nm}$ was used for IR depletion test.

\section{$D_{e}$ determination}

To obtain $D_{e}$ for quartz, the SAR protocol (Murray and Wintle, 2003) was applied to individual grains, which measures the natural signal $\left(L_{n}\right)$, a series of regenerative dose signals $\left(L_{x}\right)$ of $5,7.8,12,15.6,0$ and 5 Gy, and their corresponding test dose signals $\left(T_{x}\right)$. The equivalent dose $D_{e}$ has been determined using the initial 5-7 channels signal integrated during the fast decaying part of the OSL decay curve with an appropriate background subtracted. To estimate the decay rates of the fast and medium components, the natural OSL signal $(N)$ and the natural test dose OSL signal $\left(T_{n}\right)$ are fitted to a sum of first-order exponential components using Origin 8.0, running a Levenberg-Marquardt algorithm.

Grains were rejected if the resulting OSL data failed to satisfy the criteria similar to those proposed by (Jacobs et al., 2006), namely if: the relative uncertainty on the first test dose signal $T_{N}$ was less than three sigma above its corresponding background or its relative standard error is $>20 \%$; the recycling ratio is $>10 \%$, and the recuperation is $>10 \%$ of $\mathrm{L}_{\mathrm{N}} / \mathrm{T}_{\mathrm{N}} ;(\mathrm{C})$ the $\mathrm{L}_{\mathrm{N}} / \mathrm{T}_{\mathrm{N}}$ value exceeded the 
laboratory-measured dose-response curves; OSL / IRSL depletion ratio differed from unity by more than two sigma and the $\mathrm{TL} 110^{\circ} \mathrm{C}$ test. To check for the presence of feldspar, an IR depletion-ration test applied to the aliquot was incorporated at the end the SAR sequence (using an IRSL exposure for $100 \mathrm{~s}$ at $20^{\circ} \mathrm{C}$ ). The incorporation of TL test to check whether the feldspar component is present involved checking TL whether the range of 150 $220^{\circ} \mathrm{C}$ is at the background level (e.g. Solongo et al., 2019; $\mathrm{Hu}$ and $\mathrm{Li}, 2019$ ).

\section{RESULTS AND DISCUSSION}

\section{Quartz OSL characteristics}

\section{Quartz pottery single grains}

Fig. 1 presents the luminescence characteristics of three representative quartz grains from the pottery sample L-EVA1201. Thermal treatment and annealing of quartz might introduce enhancement in the luminescence sensitivity of annealed quartz (Bøtter-Jensen et al., 1995), and be associated with changes in the defect structures and populations (Poolton et al., 2000) and strong enhancement of the UV emission (Martini et al., 2014). For this quartz L-EVA1201, grain-to-grain variations were negligible. Altogether 300 grains were measured, as expected, the majority of the dose estimates $(60 \%)$ were accepted and the remaining 120 grains were rejected owing to the lack of an OSL response to the test dose only. The representative natural OSL, test dose OSL and test dose OSL decay curves after IR bleaching at the end of SAR sequence stimulation are shown in Fig. 1b, 1d, 1f. The signal response to IRSL at the end of SAR was negligible confirming that the grains from aliquot are not IRsensitive; in addition, the presence of the TL $110^{\circ} \mathrm{C}$ peak further confirms the absence of feldspar. LM-OSL conducted on a single grain identified dominant fast component (Fig. 1c).
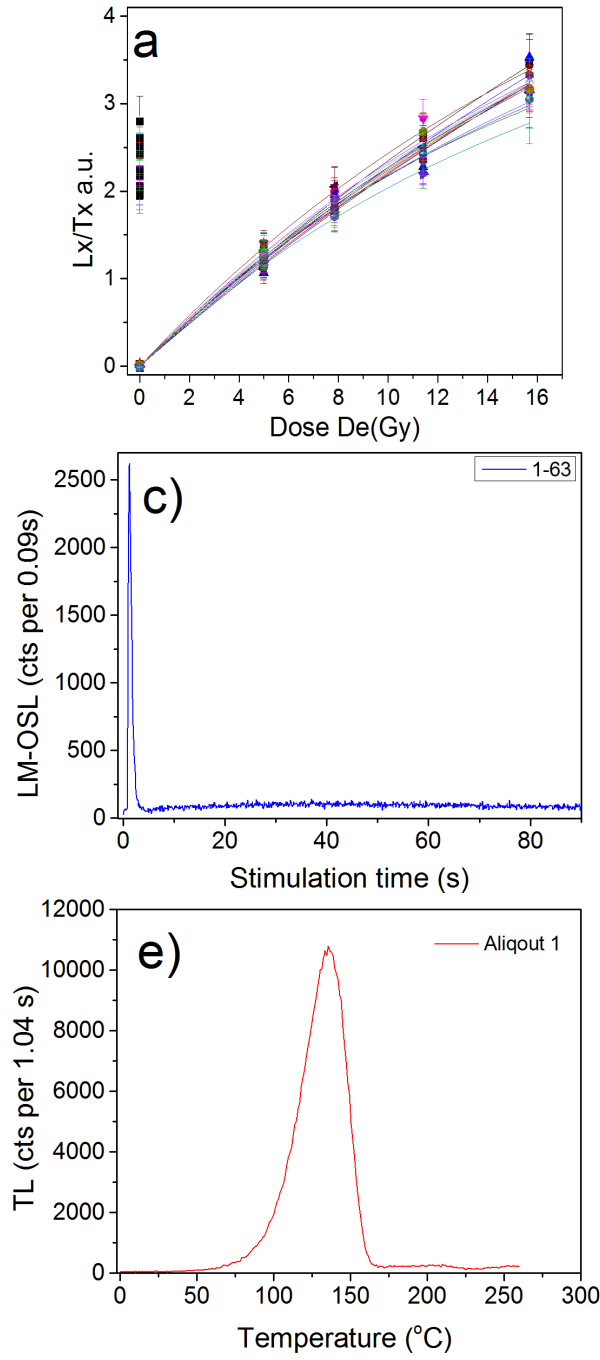
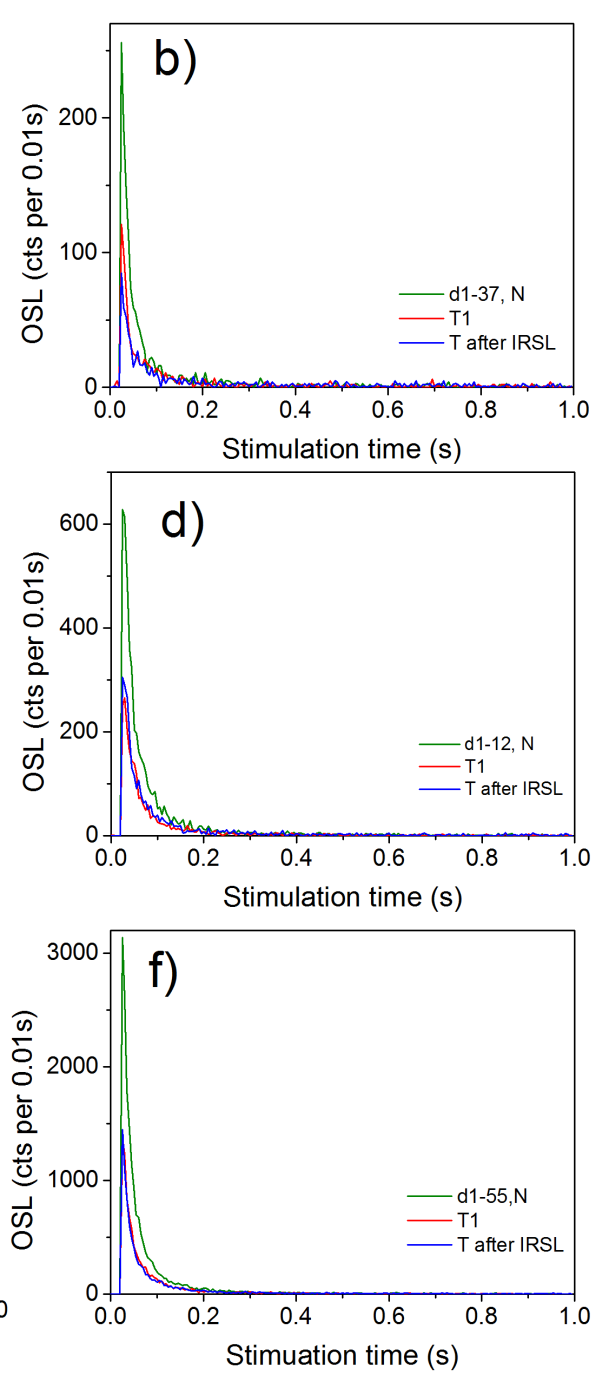

Fig. 1. The dose-response curves for individual quartz grains of the heated quartz sample L-EVA1201, showing $L_{x} / T_{x}$ as a function of regeneration doses. The corresponding luminescence decay curves from the individual grains are shown on the right side: natural OSL ( $N$ - black line), test dose $\left(T_{1}\right.$ - red line and $T$ after IRSL - blue line) OSL decay curves as a function of stimulation time obtained from single grains. In addition, the corresponding TL measured from the aliquot at the end of the SAR protocol served as additional criteria for examining the presence of feldspar. 

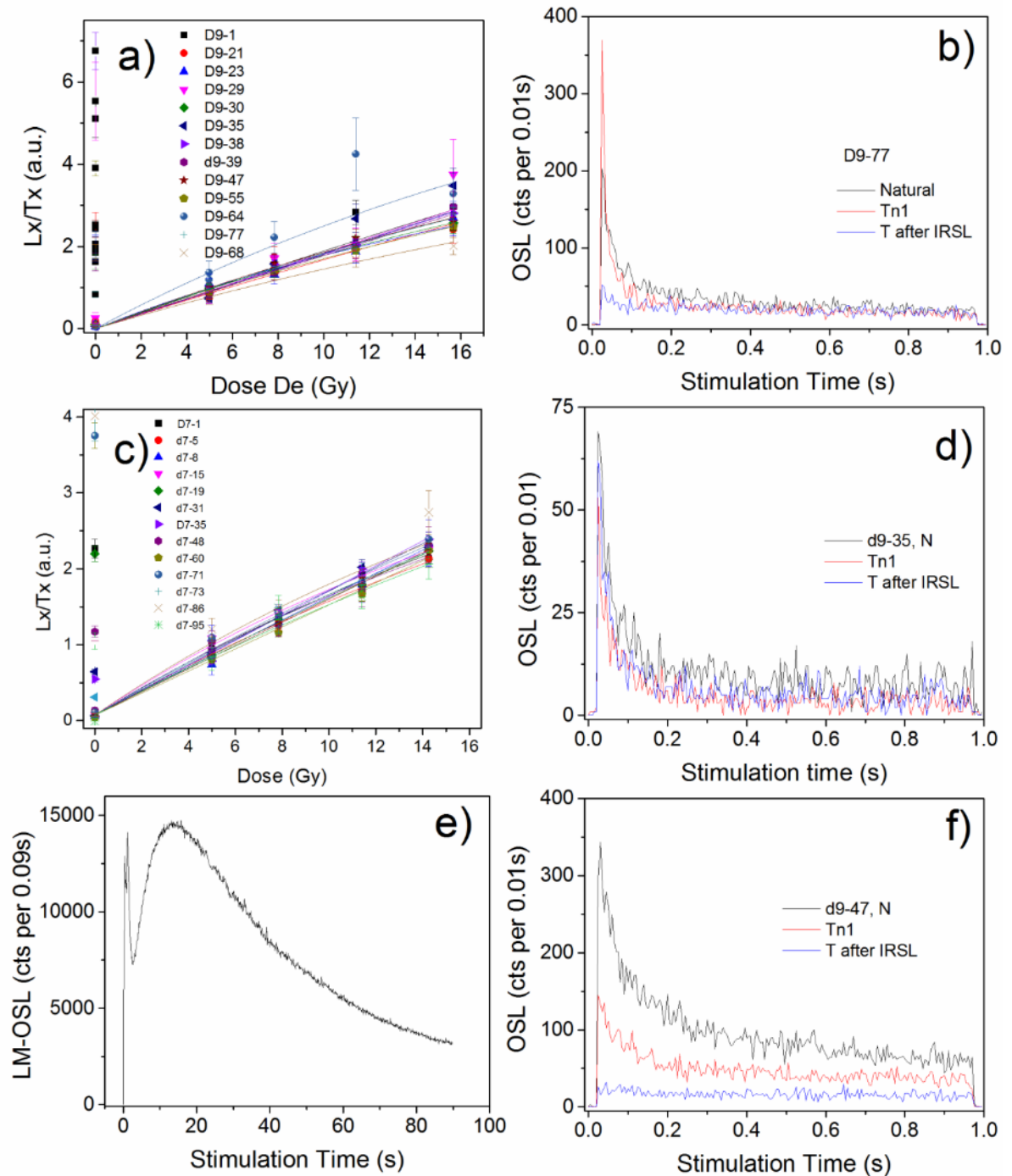

Fig. 2. a) and c) The dose-response curves for individual quartz grains of the sedimentary quartz L-EVA1202, showing $L_{x} / T_{x}$ as a function of regeneration doses. The corresponding luminescence decay curves from the individual grains are shown on the right side: natural OSL ( $N$ blue line), test dose ( $T_{1}$ - red line and $T$ after IRSL - blue line) OSL decay curves as a function of stimulation time obtained from single grains. In addition, LM-OSL from a bright grain (e) indicated the presence of a significant slow component in addition to the fast component; however those bright grains were rejected.
For each grain, the sensitivity-corrected regenerated OSL signals $\left(\mathrm{L}_{\mathrm{x}} / \mathrm{T}_{\mathrm{x}}\right)$ were fitted with a single saturatingexponential function in the form:

$I=I_{\max }\left[1-e^{\frac{D}{D_{o}}}\right]$

where $I$ is the luminescence intensity, $I_{\max }$ is the intensity at saturation, $D-$ dose, and $D_{0}-$ the characteristic dose where the intensity $I_{\max }$ is $(1-1 / \exp )$ times the saturation value. We have obtained values for $\mathrm{I}_{\max }$ of 5 to 16 and $D_{0}$ values of 24 to $70 \mathrm{~Gy}$. In addition, a global fitting procedure (Fig. 1a) was used to a selection of single grains by fitting a single saturating exponential function; the $D_{0}$ values obtained being between 16 and $40 \mathrm{~Gy}$ and the equivalent doses between 8 to $12 \mathrm{~Gy}$.

Previously, Roberts and Duller (2004) reported for multi-grain $I_{\max }$ values of 36 to 52 and $D_{0}$ values as low as 38.6-55.1 Gy. However, Burbidge et al. (2006) stud- ied younger samples and their values of $\mathrm{I}_{\max }$ and $D_{0}$ were all lower than those of Roberts and Duller (2004), and they argued that this may because the maximum regenerative dose of 64 Gy was half of that used by Roberts and Duller (2004). In our experiments, the maximum regenerative doses were of 15.6 Gy and $30 \mathrm{~Gy}$, respectively. According to the recommendation of Wintle and Murray (2006), the equivalent dose values of more than $2 D_{0}$ should be rejected because of high uncertainty, and the $D_{e}$ 's obtained from SAR and global fitting were less than $2 D_{0}$.

Following this first analysis, we calculated the dose estimates obtained when the relative uncertainty on the natural test dose, and the error in $D_{e}$, were less than 30 , 20,15 and $10 \%$, respectively. The effect of the precision on the resultant $D_{e}$ is shown in Fig. 3a where the estimated dose $D_{e}$ is plotted against the precision on $D_{e}$. As can be seen from the figure, the application of this criterion does not significantly change the CAM $D_{e}$ (Galbraith and 
Roberts, 2012) of the distribution. However, the relative spread in $D_{e}$ values increases as higher precision constraints are applied and results in a significant increase in the relative standard error of $2.7 \%$ to $7.5 \%$, as the number of accepted grains meets acceptance criteria decreased from 180 to 65 . The over-dispersion OD value reduced from 11.2 to $9.9 \pm 0.2 \%$. The most precise estimates $(5 \%)$ lead to the relative standard error of $15 \%$, which is due to the statistically irrelevant number of grains $(n=36)$.

\section{Sedimentary quartz single grains}

For the sedimentary samples L-EVA1202 and L-EVA1203, the quartz grains exhibit significant grainto-grain variability in terms of OSL decay rate and inherent brightness. The sensitivity of sedimentary quartz grains has been suggested to be associated with different factors such as the source of origin of the mineral grains (Fitzsimmons, 2011), and their sedimentary/thermal history (Sawakuchi et al., 2011). Altogether 500 grains of L-EVA1202 were measured from which 149 grains $(29.8 \%)$ were accepted. For representative 'dim' grains from the sedimentary quartz L-EVA1202 that passed the acceptance criteria, the natural OSL, test dose OSL and test dose OSL decay curves after IR stimulation are shown in Fig. 3b, 3d, 3f.

The dose-response curves of a selection of grains (L-EVA1202, Fig. 3a, 3c) were fitted using a global fitting procedure, however for some grains fitting was done by a linear equation. We obtained the values for $\mathrm{I}_{\max }$ from 6 to 28 and for $D_{0}$ from 25 to $82 \mathrm{~Gy}$, which is higher than for pottery. Most importantly, the relative scatter in $D_{e}$ for the sedimentary quartz is substantially higher than for the pottery and $D_{e}$ values range from $4.2 \pm 0.4$ Gy to
$37.3 \pm 2.5 \mathrm{~Gy}$. We believe the scatter is due to the following different sources: (i). grain-to-grain variations in luminescence properties; (ii). heterogeneous bleaching of grains, and post-depositional mixing of grains from different sources; and (iii). inhomogeneity in dose rate due to variations in ${ }^{40} \mathrm{~K}$ concentrations (Guérin et al., 2015).

Similarly, we calculated the dose estimates for precision in $D_{e}$ of 30,20 , and $10 \%$, respectively. For sedimentary sample L-EVA1202, it seems reasonable to assume that the sample is probably affected by incomplete bleaching or post-depositional mixing. Therefore the MAM and FFM $D_{e}$ 's are analysed, as shown in Fig. 3b. It is a trend to observe that both the MAM $D_{e}$ and FMM $D_{e}$ values increase as higher precision is applied, and the number of accepted grains decreases from 146 to 53 . It is noted that FMM $D_{e}$ values yielded $5.14 \pm 0.38$ Gy that are consistent with for precision at 15,20 , and $30 \%$. In contrast, the probably the well-bleached grains with the highest precision (error on $D_{e}<10 \%$ ) yield higher values of $7.64 \pm 0.38 \mathrm{~Gy}$.

It is worth to note that 51 grains (with signals up to 30,000 cts in the first $0.035 \mathrm{~s}$ of stimulation of the natural signal) were registered; however, these bright grains failed the rejection criteria; specifically, the sensitivitycorrected natural signal does not result in a finite dose estimate. In addition, the bright grains failed the TL $110^{\circ} \mathrm{C}$ test and the IR depletion test, suggesting the presence of a feldspar component. The LM-OSL measurements from a bright grain (Fig. 3f) indicated the presence of a significant slow component in addition to the fast component; this is in contrast to pottery grains, where the presence of a dominant fast component was confirmed. However, the detailed investigation of those bright grains using LM-OSL is beyond the scope of this paper.
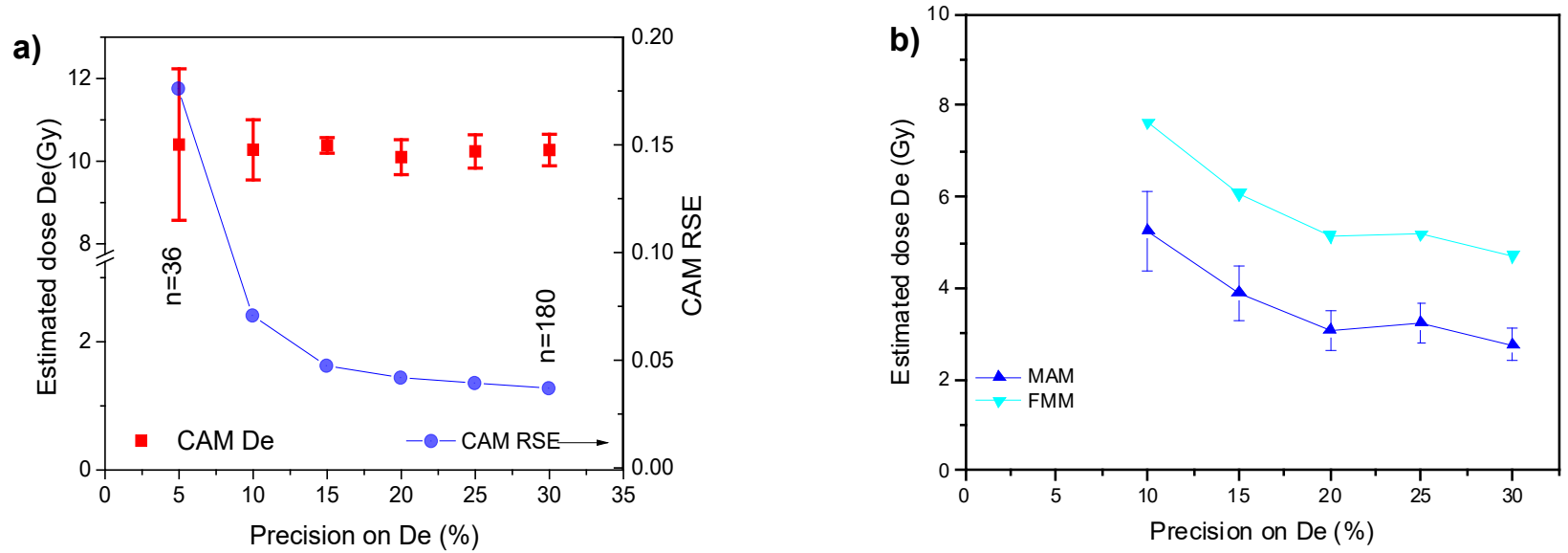

Fig. 3. Effect of precision on $D_{e}$ a). for sample L-EVA1201. Central Age Model (CAM, squares) dose and the relative standard error (as circles) on $\left.C A M D_{e} ; b\right)$. for sample L-EVA1202. FMM and MAM $D_{e}$ (triangles and squares) as function of precision on $D_{e}$. 
a)
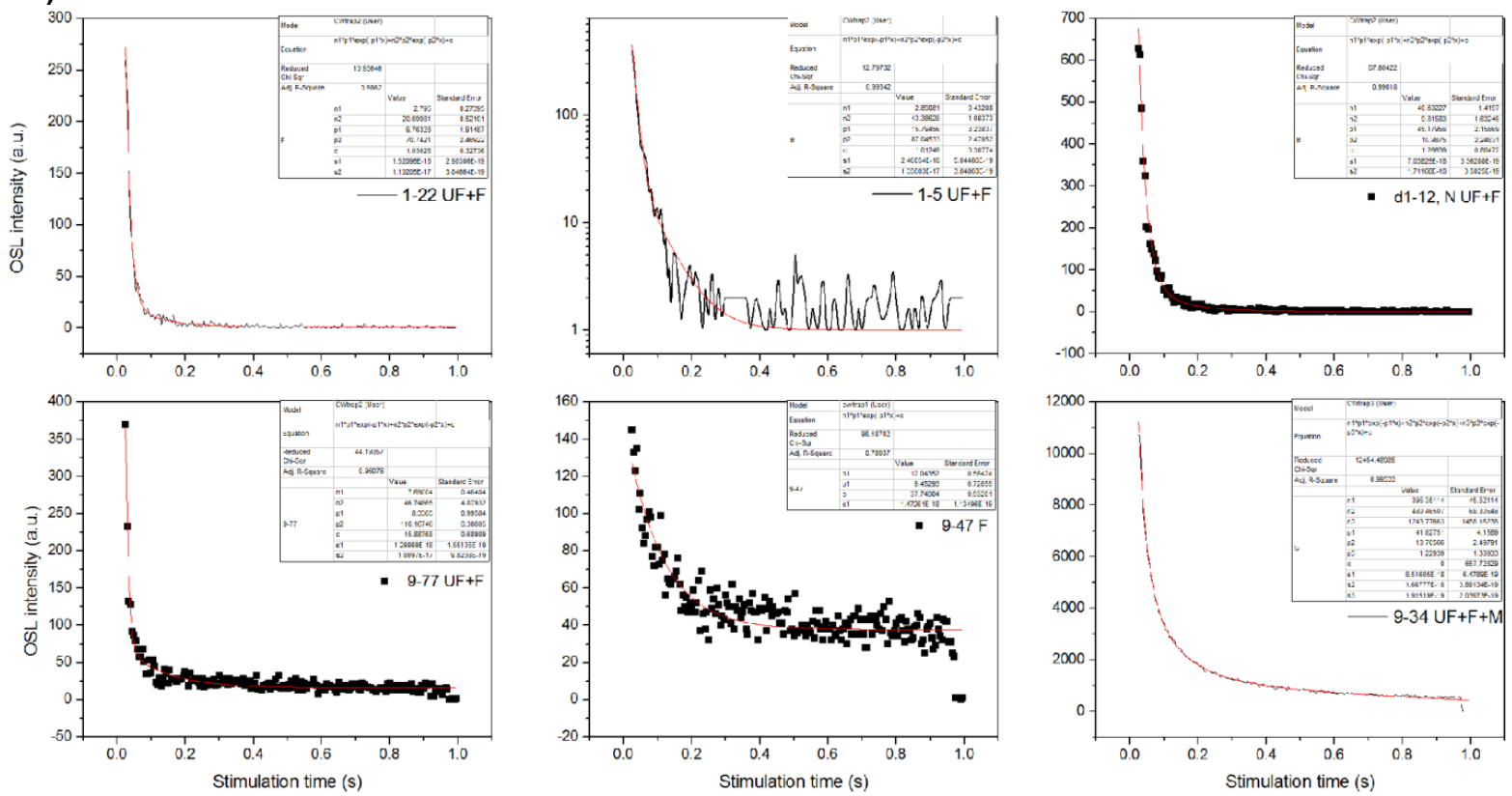

b)
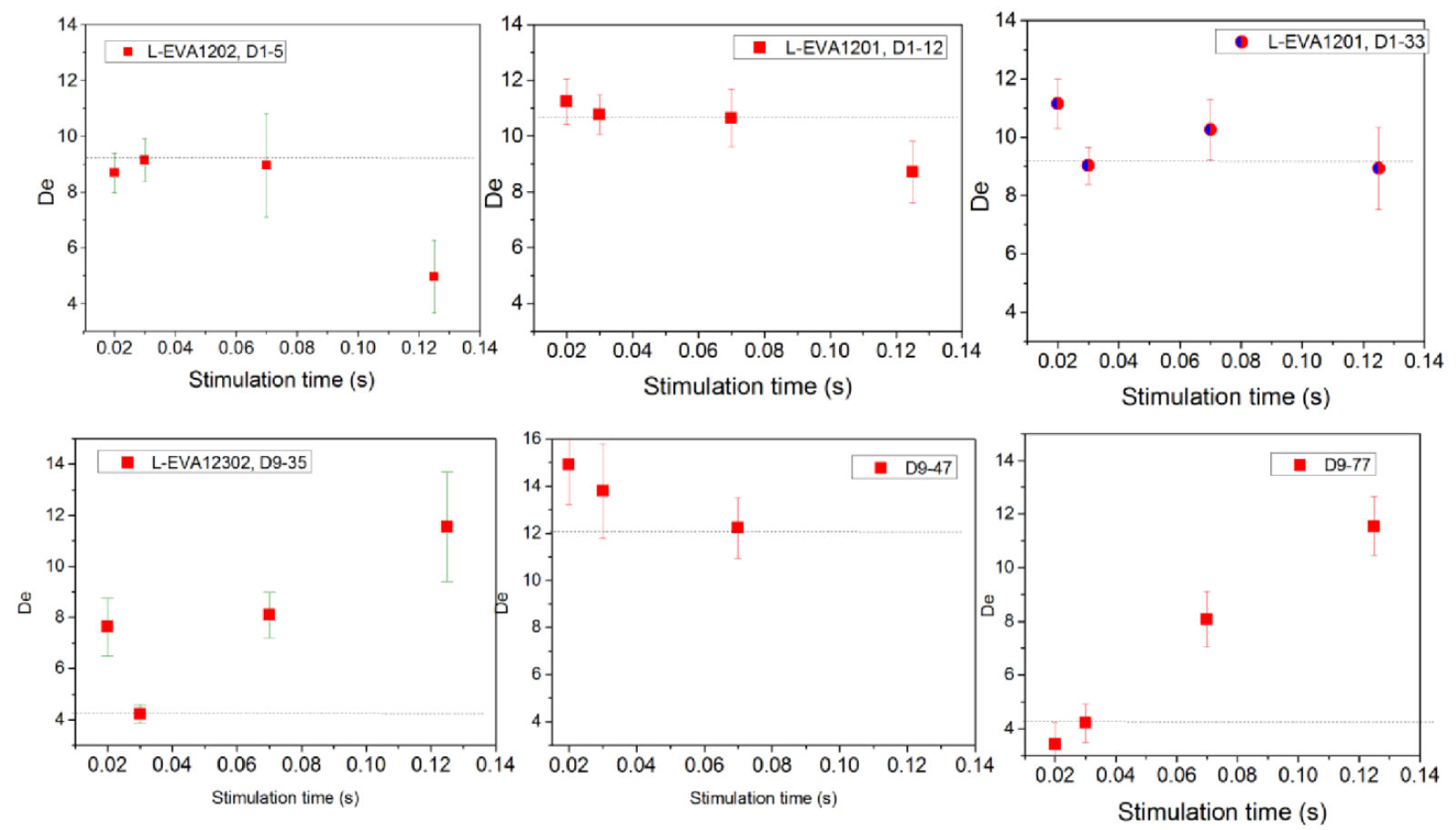

Fig. 4. a) The fitting results for pottery L-EVA1201, and for sedimentary quartz LEVA1202 showing the presence of UF, F and medium OSL components. b) The corresponding constant and increasing De-t-plots for L-EVA1201 and L_EVA1202 are shown. 


\section{Presence of an ultrafast quartz OSL component}

The addition of the 'fast ratio' (Durcan and Duller, 2011) and thus removing the grains with low fast ratios as a criterion for selecting single grains for dose estimation was proposed recently (Duller, 2012); however, it might also lead to the removal of a high proportion of signals (Thomsen et al., 2016). The application of "fast ratio" by calculating the ratio between the fast and medium bleaching components for each grain from both datasets was tested here.

The results of the fitting showed up to three components with decay rates on average of $53 \pm 1 \mathrm{~s}^{-1}$, $13.4 \pm 0.7 \mathrm{~s}^{-1}$ and $1.2 \pm 0.2 \mathrm{~s} \mathrm{~s}^{-1}$. Our results are in agreement with the decay rates of $10.3 \pm 3.4 \mathrm{~s}^{-1}$ for the fast and $2.1 \pm 0.7 \mathrm{~s}^{-1}$ for the medium components reported by (Feathers and Pagonis, 2015), and of $11 \pm 4.3 \mathrm{~s}^{-1}$ and $1.9 \pm 1.0 \mathrm{~s}^{-1}$ obtained by (Duller, 2012). We assume that the additional component with the decay rate of $56.6 \pm 2.4 \mathrm{~s}^{-1}$ obtained in our measurements may correspond to a very rapidly decaying ultrafast OSL (UF component) in quartz samples, reported earlier for multi-grain OSL by (Jain et al., 2008).

This ultrafast component was identified in samples from different areas around the world, and the optical cross-section of the responsible trap under blue light stimulation is about 14 times larger than that of the fast component (Jain et al., 2008). For dating, the authors suggested removing the UF component by IR bleaching above room temperature, removing by high preheat temperature $\left(>200^{\circ} \mathrm{C}\right)$ or rejection of the very initial OSL signal. Interestingly, the preheat did not remove the hypothesised UF component; SAR protocol used in our studies employed preheat at $260^{\circ} \mathrm{C}$ and cut heat at $220^{\circ} \mathrm{C}$, and these preheats are assumed to be high enough to remove the UF component (Jain et al., 2008). This implies that this UF is a) different to Jain et al.'s (2008) and b) that is reasonably thermally stable. Further tests are needed, e.g. high-temperature IR sine IR stimulation at room temperature did not impact the UF. The only evidence that this is a component other than the fast component is the fitting results and the proof of an additional component to the previously reported one.

The initial OSL signal integration interval is assumed to include the fast component preferentially, and rejection of the very initial OSL signal might remove the UF. In the following we examined the effect of variation for the integration intervals on $D_{e}$ estimation i.e. using the initial part $(0.025 \mathrm{~s}$, i.e. channels $6-7)$ for ultrafast and by rejecting the initial part (integrating $0.03-0.035 \mathrm{~s}$, i.e. channels 7-9) of stimulation to isolate the UF and fast components.

The results are displayed in Fig. 4. We examined the effect of variation for the integration intervals on $D_{e}$ estimation for pottery L-EVA1201, and for sedimentary quartz LEVA1202 and the corresponding using the $\mathrm{D}_{\mathrm{e}}-\mathrm{t}-$ plots are shown.

\section{$D_{e}$ estimates using UF and fast components as radial plots}

\section{Comparison of growth curve and radial plots}

Fig. 5 compares growth curves for pottery L-EVA1201 and sedimentary L-EVA1202. For pottery, the growth curve was fitted by a single saturating exponential function of $y=5.8[1-\exp / 20.9]$, whereas the sedimentary quartz was fitted using a linear function $\mathrm{y}=0.03+0.19 \mathrm{x}$.

Fig. 6a displays a radial plot; the CAM $D_{e}$ derived from the 'fast' and 'ultrafast' components were $9.8 \pm 0.2 \mathrm{~Gy}$ and $\mathrm{OD}=14.7 \%$ which is consistent with the CAM $D_{e}$ of $9.9 \pm 0.1 \mathrm{~Gy}$ and $\mathrm{OD}=15 \%$ for UF.

In contrast, Fig. 6b shows radial plot; $n=135$ out of 500; CAM $D_{e}$ is $15.1 \pm 1.5$ Gy with $\mathrm{OD}=96.8 \%$, suggesting the use of MAM $D_{e}$ which is $5.9 \pm 1.3 \mathrm{~Gy}$.

\section{CONCLUSIONS}

The archaeological site at the Khutag Uul Mountains (Mongolia) was investigated using single-grain quartz OSL on pottery and sedimentary samples. Detailed luminescence investigations revealed a presence of an ultrafast component - not detected previously in the single grain measurements - which might lead to erroneous 'fast ratio' estimates. As the fitting results of pottery quartz display, fitting was done using ultrafast, fast plus background. It is worth mentioning that the introduction of the third component, namely the medium or slow component did not improve the fit and was equal the background. For the sedimentary quartz grains, fitting was done using a combination of ultrafast and medium with a small fast contribution, whereas the other datasets were fitted using fast and medium components only. Therefore, it was impossible to obtain fast ratio values for the whole dataset.

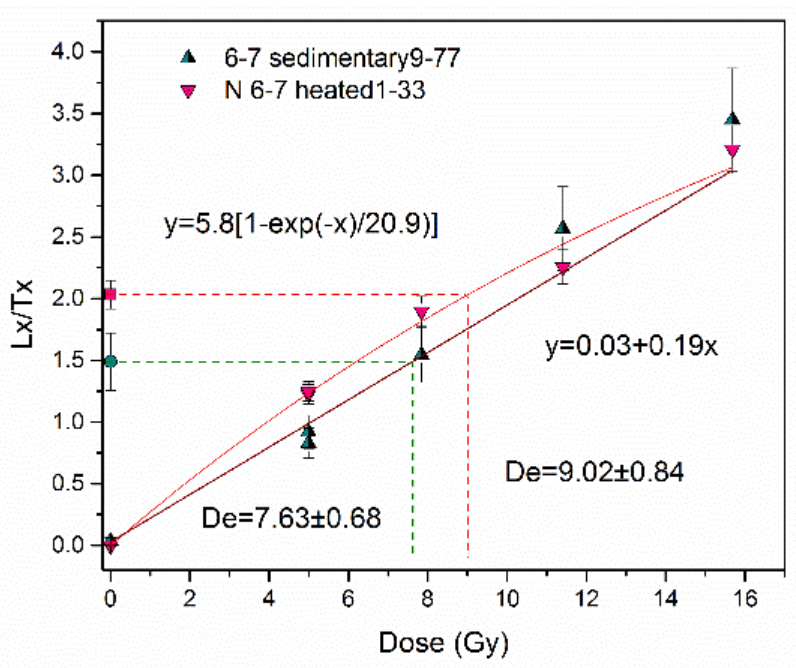

Fig. 5. Growth curves for naturally sedimentary and heated quartz grains. 

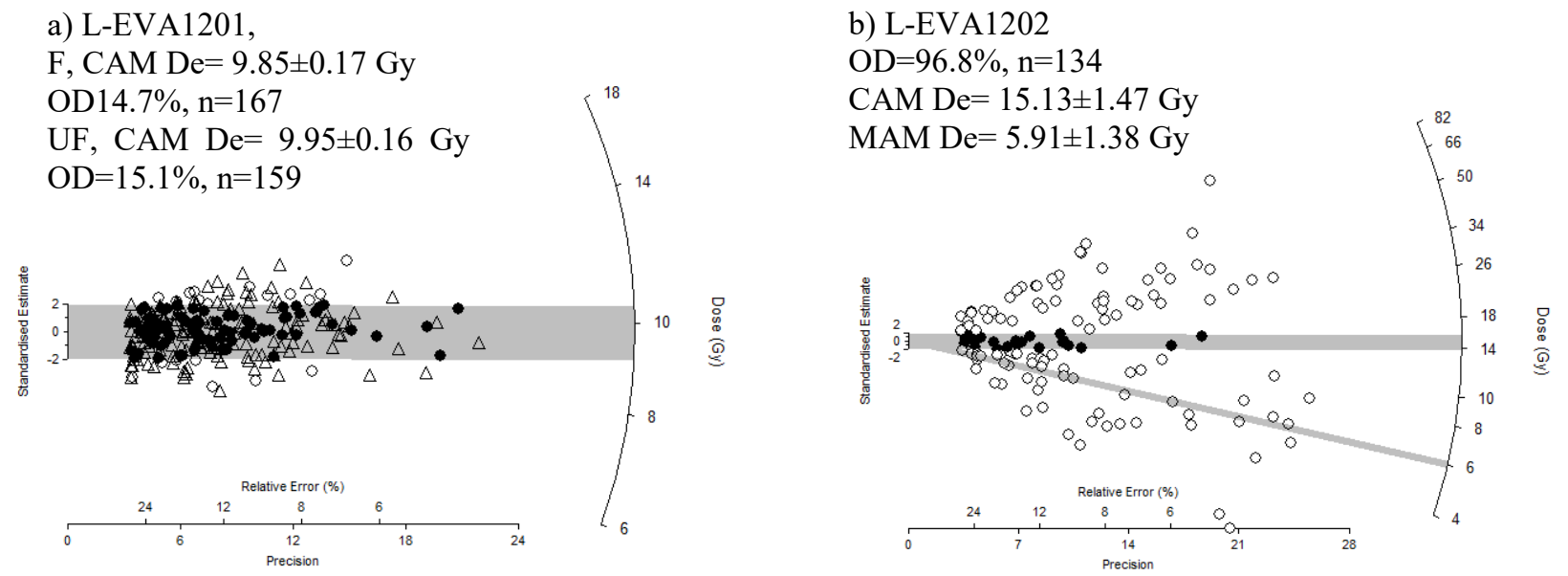

Fig. 6. Radial plots of the single grain dose distributions a) fast $D_{e}$ from accepted 167 grains (closed triangles) for heated quartz L-EVA1201 and UF $D_{e}$ from $n=159$ (circles). The solid grey band is centered on the weighted mean, $D_{e}$ determined using Central Age Model, over-dispersion of $14.7 \%$. b) $D_{e}$ from accepted 134 grains of L-EVA1202 channels 6-9. The solid grey lines indicate the CAM $D_{e}=15.13 \pm 1.47$ Gy and overdispersion of 96.8\%. MAM $D_{e}=5.91 \pm 1.38 \mathrm{~Gy}$.

The CAM $D_{e}$ derived from the 'fast' and 'ultrafast' components were $9.8 \pm 0.2$ Gy and $\mathrm{OD}=14.7 \%$ which is consistent with the CAM $D_{e}$ of $9.9 \pm 0.1$ Gy and $\mathrm{OD}=15 \%$ for UF. In contrast, for sedimentary quartz where the MAM $D_{e}$ and FMM $D_{e}$ were taken into consideration, rejecting the initial part in order to remove the UF lead to reduce the number of selected grains, which might thus lead to a loss of robustness in the final results.

\section{SUPPLEMENTARY MATERIAL}

Supplementary material, containing additional tables is available online at http://dx.doi.org/10.1515/geochr2015-0117.

\section{ACKNOWLEDGEMENTS}

The attendance of S.Tengis to APLED Beijing was financed by TWAS Research Grant: 17-521RG/ PHYS/ AS_G-FR3240300144. This study was partially funded by Grant SS2017/63 from the Science and Technology Foundation of Mongolia to Saran Solongo. SaS thanks Prof. J-J Hublin and Max Planck Institute for evolutionary anthropology for providing access to the Luminescence facilities.

\section{REFERENCES}

Adamiec G, 2005. OSL decay curves - relationship between single- and multiple-grain aliquots. Radiation Measurements 39: 63-75, DOI 10.1016/j.radmeas.2004.03.007.

Adamiec G, Duller GAT, Roberts HM and Wintle AG, 2010. Improving the TT-OSL SAR protocol through source trap characterisation. Radiation Measurements 45: 768-777, DOI 10.1016/j.radmeas.2010.03.009.
Arnold LJ and Roberts RG, 2009. Stochastic modelling of multi-grain equivalent dose (De) distributions: Implications for OSL dating of sediment mixtures. Quaternary Geochronology 4: 204-230, DOI 10.1016/j.quageo.2008.12.001.

Bailey RM, Yukihara EG and McKeever SWS, 2011. Separation of quartz optically stimulated luminescence components using green (525 nm) stimulation. Radiation Measurements 46: 643-648, DOI 10.1016/j.radmeas.2011.06.005.

Bayar D, Munkhtulga R, Khurelsukh S, Bayarsukh, N, 2010. Report of the joint Mongol-Kazakhsan expedition in 2009.

Bøtter-Jensen L, Agersnap Larsen N, Mejdahl V, Poolton NRJ, Morris MF and McKeever SWS, 1995. Luminescence sensitivity changes in quartz as a result of annealing. Radiation Measurements 24: 535-541, DOI 10.1016/1350-4487(95)00006-Z.

Bøtter-Jensen L, Andersen CE, Duller GAT and Murray AS, 2003. Developments in radiation, stimulation and observation facilities in luminescence measurements. Radiation Measurements 37: 535541, DOI 10.1016/S1350-4487(03)00020-9.

Bulur E, Duller GAT, Solongo S, Bøtter-Jensen L and Murray AS, 2002. LM-OSL from single grains of quartz: a preliminary study. Radiation Measurements 35: 79-85, DOI 10.1016/S13504487(01)00256-6.

Burbidge CI, Duller GAT and Roberts HM, 2006. De determination for young samples using the standardised OSL response of coarsegrain quartz. Radiation Measurements 41: 278-288, DOI 10.1016/j.radmeas.2005.06.038.

Duller GAT, 2008. Single-grain optical dating of Quaternary sediments: why aliquot size matters in luminescence dating. Boreas 37: 589612, DOI 10.1111/j.1502-3885.2008.00051.x.

Duller GAT, 2012. Improving the accuracy and precision of equivalent doses determined using the optically stimulated luminescence signal from single grains of quartz. Radiation Measurements 47: 770777, DOI 10.1016/j.radmeas.2012.01.006.

Durcan JA and Duller GAT, 2011. The fast ratio: A rapid measure for testing the dominance of the fast component in the initial OSL signal from quartz. Radiation Measurements 46: 1065-1072, DOI 10.1016/j.radmeas.2011.07.016.

Feathers JK and Pagonis V, 2015. Dating quartz near saturation Simulations and application at archaeological sites in South Africa and South Carolina. Quaternary Geochronology 30: 416-421, DOI 10.1016/j.quageo.2014.12.008. 
Fitzsimmons KE, 2011. An assessment of the luminescence sensitivity of Australian quartz with respect to sediment history. Geochronometria 38: 199-208, DOI 10.2478/s13386-011-0030-9.

Galbraith RF and Roberts RG, 2012. Statistical aspects of equivalent dose and error calculation and display in OSL dating: An overview and some recommendations. Quaternary Geochronology 11: 1-27, DOI 10.1016/j.quageo.2012.04.020.

Guérin G, Discamps E, Lahaye C, Mercier N, Guibert P, Turq A, Dibble HL, McPherron SP, Sandgathe D, Goldberg P, Jain M, Thomsen K, Patou-Mathis M, Castel J-C and Soulier M-C, 2012. Multimethod (TL and OSL), multi-material (quartz and flint) dating of the Mousterian site of Roc de Marsal (Dordogne, France): correlating Neanderthal occupations with the climatic variability of MIS 5-3. Journal of Archaeological Science 39: 3071-3084, DOI 10.1016/j.jas.2012.04.047.

Guérin G, Jain M, Thomsen KJ, Murray AS and Mercier N, 2015. Modelling dose rate to single grains of quartz in well-sorted sand samples: The dispersion arising from the presence of potassium feldspars and implications for single grain OSL dating. Quaternary Geochronology 27: 52-65, DOI 10.1016/j.quageo.2014.12.006.

$\mathrm{Hu} \mathrm{G}$ and $\mathrm{Li} \mathrm{S}-\mathrm{H}, 2019$. Simplified procedures for optical dating of young sediments using quartz. Quaternary Geochronology 49: 3138, DOI 10.1016/j.quageo.2018.03.009.

Jacobs Z, Duller GAT and Wintle AG, 2006. Interpretation of single grain distributions and calculation of. Radiation Measurements 41: 264-277, DOI 10.1016/j.radmeas.2005.07.027.

Jacobs Z and Roberts RG, 2007. Advances in optically stimulated luminescence dating of individual grains of quartz from archeological deposits. Evolutionary Anthropology 16: 210-223, DOI 10.1002/evan.20150.

Jacobs Z, Roberts RG, Nespoulet R, El Hajraoui MA and Debénath A, 2012. Single-grain OSL chronologies for Middle Palaeolithic deposits at El Mnasra and El Harhoura 2, Morocco: Implications for Late Pleistocene human-environment interactions along the Atlantic coast of northwest Africa. Journal of Human Evolution 62: 377-394, DOI 10.1016/j.jhevol.2011.12.001.

Jain M, Choi JH and Thomas PJ, 2008. The ultrafast OSL component in quartz: Origins and implications. Radiation Measurements 43: 709-714, DOI 10.1016/j.radmeas.2008.01.005.

Martini M, Fasoli M and Villa I, 2014. Defect studies in quartz: Composite nature of the blue and UV emissions. Nuclear Instruments and Methods in Physics Research Section B: Beam Interactions with Materials and Atoms 327: 15-21, DOI 10.1016/j.nimb.2013.09.048.
Murray AS and Wintle AG, 2003. The single aliquot regenerative dose protocol: potential for improvements in reliability. Radiation Measurements 37: 377-381, DOI 10.1016/S1350-4487(03)00053-2.

Poolton NRJ, Smith GM, Riedi PC, Bulur E, Bøtter-Jensen L, Murray AS and Adrian M, 2000. Luminescence sensitivity changes in natural quartz induced by high temperature annealing: a high frequency EPR and OSL study. Journal of Physics D: Applied Physics 33: 1007-1017, DOI 10.1088/0022-3727/33/8/318.

Roberts H and Duller G, 2004. Standardised growth curves for optical dating of sediment using multiple-grain aliquots. Radiation Measurements 38(2): 241-252, DOI 10.1016/j.radmeas.2003.10.001.

Sawakuchi AO, DeWitt R and Faleiros FM, 2011. Correlation between thermoluminescence sensitivity and crystallization temperatures of quartz: Potential application in geothermometry. Radiation Measurements 46: 51-58, DOI 10.1016/j.radmeas.2010.08.005.

Solongo S, Erdene-Ochir N-O, Tengis S, Hublin J-J, 2019. Testing the pIRIR on pottery and SG-OSL on clay sediment from the known age Xiongnu "Royal" tomb at Noin-Ula, Mongolia. Archaeological and Anthropological Sciences 11: 811-821, DOI 10.1007/s12520-017-0570-x.

Solongo S, Ochir A, Tengis S, Fitzsimmons K and Hublin J-J, 2016. Luminescence dating of mortar and terracotta from a Royal Tomb at Ulaankhermiin Shoroon Bumbagar, Mongolia. STAR: Science \& Technology of Archaeological Research 2: 235-242, DOI 10.1179/2054892315Y.0000000004.

Solongo S, Richter D, Tuguldur B and Hublin JJ, 2014. OSL and TL characteristics of fine grain quartz from Mongolian prehistoric pottery used for dating. Geochronometria 41: 15-23, DOI 10.2478/s13386-013-0119-4

Solongo S, Wagner GA and Galbaatar T, 2006. The estimation of De using the fast and medium components in fired quartz from archaeological site Karakorum, Mongolia. Radiation Measurements 41: 1001-1008, DOI 10.1016/j.radmeas.2006.05.023.

Thomsen KJ, 2004. Optically stimulated luminescence techniques in retrospective dosimetry using single grains of quartz extracted from unheated materials.

Thomsen KJ, Murray AS, Buylaert JP, Jain M, Hansen JH and Aubry T, 2016. Testing single-grain quartz OSL methods using sediment samples with independent age control from the Bordes-Fitte rockshelter (Roches d'Abilly site, Central France). Quaternary Geochronology 31: 77-96, DOI 10.1016/j.quageo.2015.11.002.

Wintle AG and Murray AS, 2006. A review of quartz optically stimulated luminescence characteristics and their relevance in singlealiquot regeneration dating protocols. Radiation Measurements 41: 369-391, DOI 10.1016/j.radmeas.2005.11.001. 